\title{
تصنيف (Classification) "أولي الألباب" وتحليل دلالي للآيات القرآنية وتطبيقها في تشكيل المثقف المسلمي (Muslim Intellectuals) والثربية الإسلامية
}

Ahmadi

Dosen STIT Muhammadiyah Pacitan

ahmadipct@gmail.com

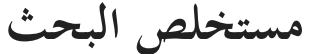

تمدف هذه المقالة المتواضعة إلى أن يصف الباحث عن تصنيف مصطلح "أولو الباب" في كثير من آيات القرآن. ومن أجل هذه الأهمية استخدم التفسير الموضوعي وتصنيفه اللغة العربية. فالخطوات متمثلة في جمع ستة عشر آيات من القرآن التي ترتبط بمعنى "أولو الباب"، تصنف كل من هذه الكلمات وفقا لموقفها من الجملة. وبذه الخطوة، سيتم الكشف عن مفهوم "أولو الألباب" بشكل كامل، وسيكون فهم مصطلح "أولو الألباب" أسهل للفهم. وبني "أولو الألباب" على التحليل النحوي، وفقًا لموقعه من الجملة كمنادى والفاعل واصفة والخبر. وانطالاقا من هذا التحليل، يشمل "أولى الألباب" معنى "الراسخين في العلم وقوام يتفكرون وأهل الذكر وأصحاب العقول". وتبين محا سبق ذكره، أن الكلمات السابقة تدل على معاني التي تشمل مبادئ الأنشطة التعليمية وأهدافها الواضحة ، هي أن يبعل إنسانا صالحا بمعارف تنفع الحياة البشربة قاطبة. الكلمات الأساسية: أولو الألباب، التحليل الدلالي، والتربية الإسالامية

أساسيات البحث

أ. أمقدمة المقة

القرآن هو المصدر المتيني والممثلي جدا (representative) عند المسلم وتقديره العالي عند عقل الإنسان، حتى يعطي التمييز لأولئك الذين يعلمون والذين لا يعلمون،

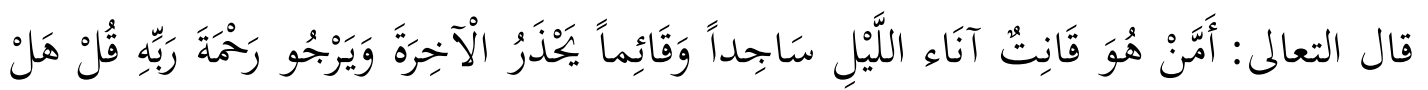

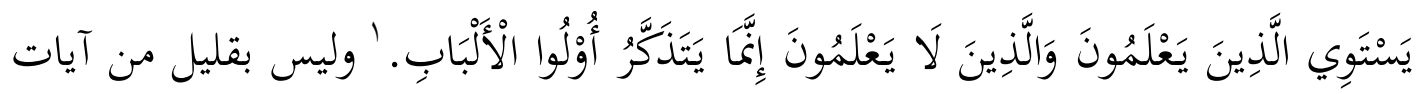


القرآن الكريم والأحاديث النبوية الشريفة يدعو إلى تشجيع الناس على استخدام عقولم

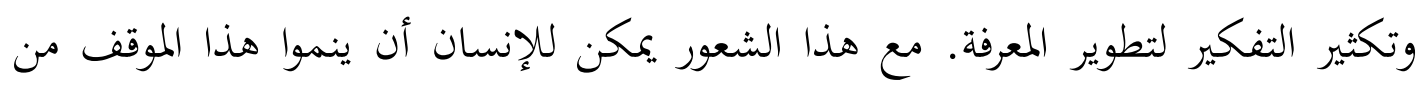

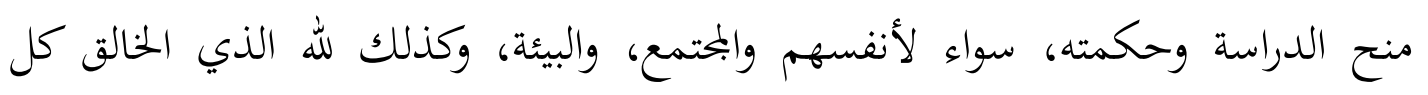
الشيء.

المعرفة المكتسبة عن طريق استخدام العقل البشري هو السبيل لتحقيق مستقبل

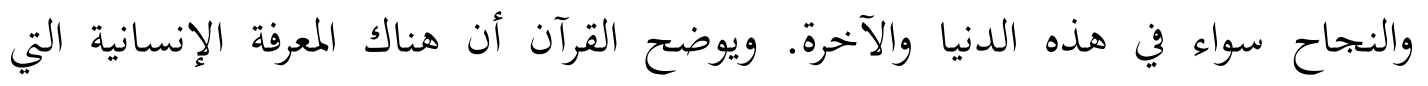

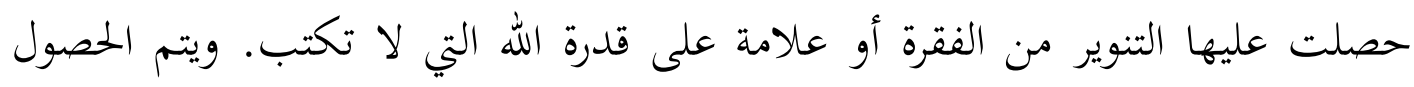

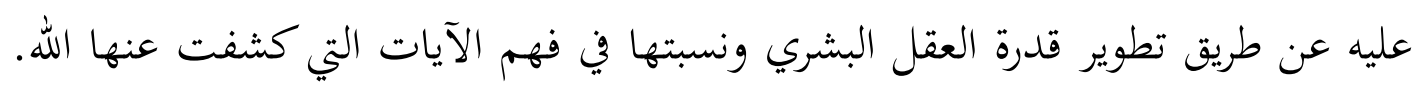
وأعرب استخدام قدرة العقل على اكتساب المعرفة المنهجية مع العلوم الأخرى.

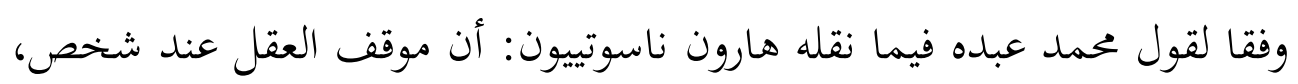
نفس المعنى بموقف النبي للأمة. الفكر هو الحياة المشتركة الأساسية والاستمرارية للإنسان.

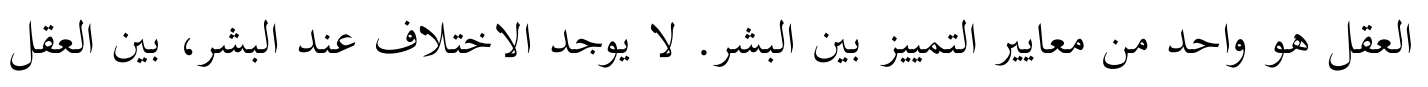

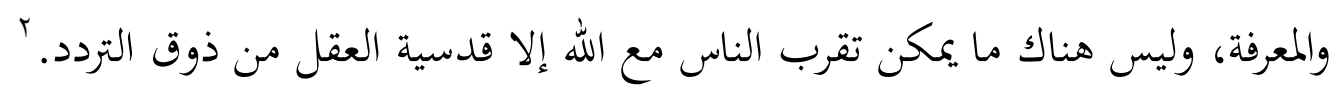

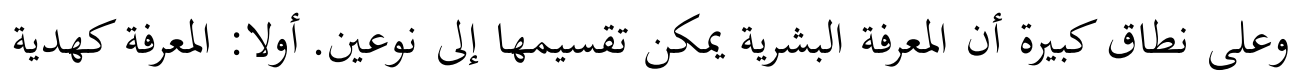

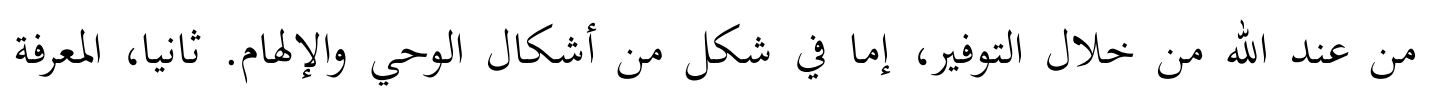

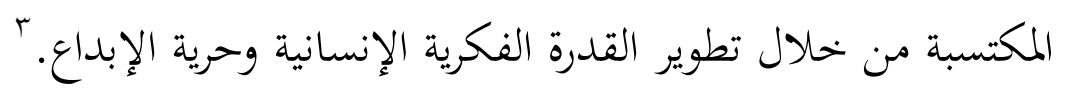
يكشف القرآن ليس بقليل من الآيات بشأن تصنيف أولو الألباب. يتم تحميل

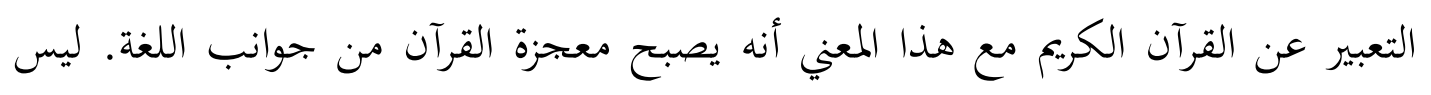

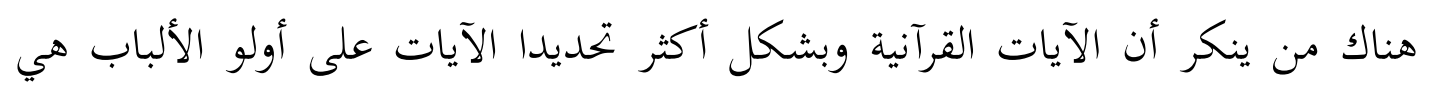

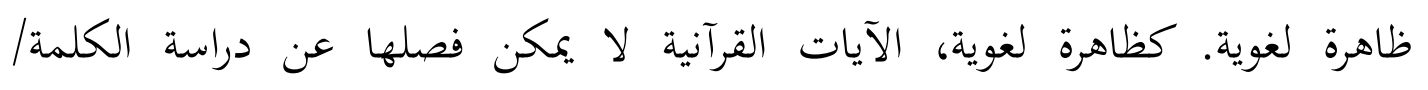

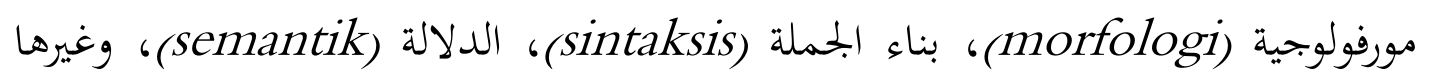
من مختلف علوم اللغة.

\footnotetext{
${ }^{2}$ Harun Nasution, Akal dan wahyu dalam Islam, (Yogyakarta: UII Press, 1997) 97

3 Abdul Munir Mulkan, Paradigma Intelektual Muslim; Pengantar Filsafat Pendidikan Islam dan Dakwah, (Yogyakarta: Sipres, 1994) 199
} 
وبشكل أكثر تحديدا يعتبر التحليل الدلالي اليوم كعنصر من عناصر اللغة التي لا يمكن تصريفها في دراسة اللغويات. دون مناقشة معنى، لا يعتبر النقاث لغوية كاملة لأن عملا فعليا من يتحدث هو شيء آخر غير ححاولة لنقل المعاني. التحليل الدلالي وفقا لقول إيزوتسو: ستشكل الكائن الأنطولوجيا موجود على مستوى ملموس، كما وردت في آيات القرآن الكريك.

في محاولة لفهم محتوى النص من القرآن الكريم، وقواعد اللغة أيضا دورا حيويا جدا. مكلمة معينة في القرآن قد تكون مختلفة من حيث الهيكل أو القواعد من غيرها من الآيات. من هذه الظاهرة، وتقدم إليها لقواعد اللغة في نقاث قضية أولي الألباب مهم جدا لأن هذه الكلمة كثيرة توجد في القرآن الكريم.

تنفيذ دراسة أولو الألباب في التربية الإسلامية هو الجههد الذي أبجبت عملية التعلم التي قدف إلى جلب الإنسان على أن يكون إمكانات شخصية المحتملين فكرية (التوجه المثقفي/intellectual oriented). من خحلا نقل المعرفة في نفس الوقت تؤدي إلى تكوين شخصية أفراد البحتمع من الأخلاقية، والجمالية من خلال نقل القيمة. ج وهذا الحال يناسب مع الخطوة من مبادئ نظام التعليم الإسلامي الذي هو ضرورة لاستخدام منهج الشامل للإنسان والذي يشمل جانب المادية الروحية، وكذلك جانب الخارجية، الداخلية.

عندما يطلع الإنسان نص القرآن الكريم من كلمة أولو الألباب ومن ثم مقارنتها للمشاكل التي تواجه التربية الإسلامية، سواء كانت الصورة التي عرضت القرآن تم تحيينها في التربية الإسالامية من خلال المفاهيم التي قدمت؟ هذه المشكلة تتطلب حلول دقيقة لمعرفة النقاط المضيئة من خلال تعزيز أو تفضيل القرآن كمالمرجع الرئيسي.

${ }^{4}$ Toshihiko Izutsu, Relasi Tuhan dan Manusia: Pendekatan Semantik terhadap Al-Qur'an, Penerj. Agus Fahri Husein, dkk (Yogyakarta: Tiara Wacana, 2003) 3.

${ }^{5}$ Komaruddin Hidayat, Memahami Bahasa Agama sebuah kajian Hermeneutik (Jakarta: Paramadina, 1996) 163

${ }^{6}$ Muslih Usa \& Aden Wijdan SZ, 1997, Pendidikan Islam Dalam Peradaba Industrial, Yogyakarta, Aditya Media, 9

${ }^{7}$ Masthuhu, Dinamika Sistem Pendidikan Pesantren (Jakarta: INIS, 1994). 27 
تمدف هذه الدراسة أو المقالة الخفيفة البسيطة إلى مضيئة التصورات ورفضت كل

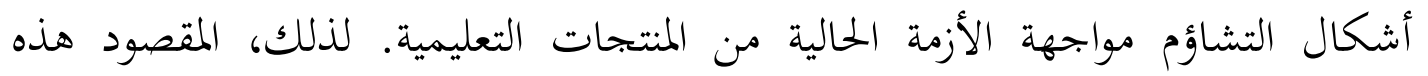
الأبحاث إلى تطوير نظرية للتعليم يقوم على تقييم الآيات القرآنية حول كلمة أولي الألئل الألباب.

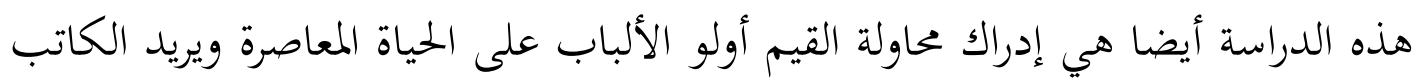

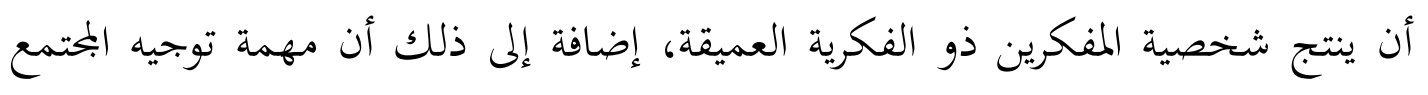
من أجل إيجاد الوعي الجماعي لصالح عالميا.

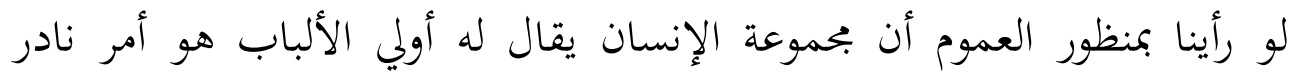

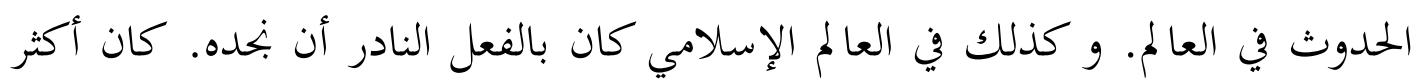
البشر الذين يفكرون ويفتش المعرفة، فقط قصيرة ومحدودة جدا بسبب الانشغال الحياة

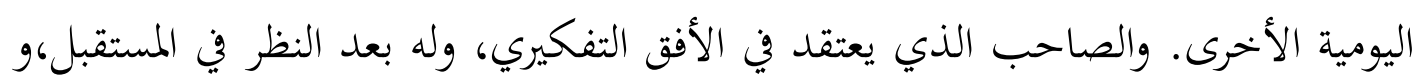
الواقع يمكن تصنيفه على أنه أولو الألباب.

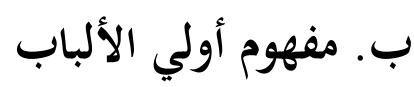

تتكون كلمة أولو الألباب من كلمتين، وهما أولو و الألباب. كلمة أولو عديدة

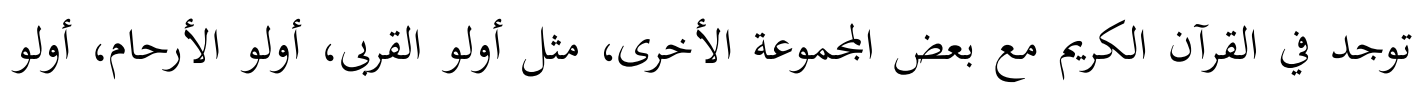

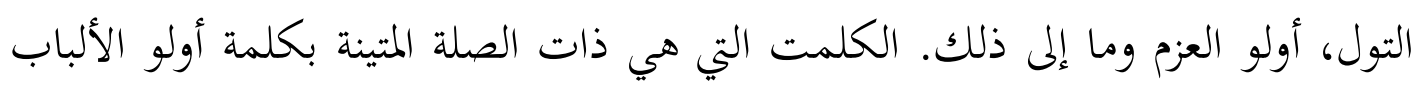

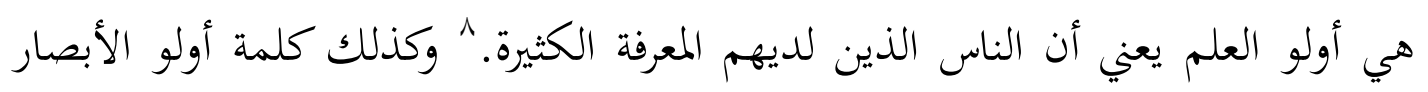

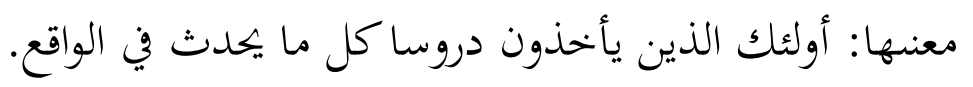
وكلمة لبّ متجذرة من كلمة لباب ومعنى هذه كلمة هي الحالة الثابتة، والنقاء،

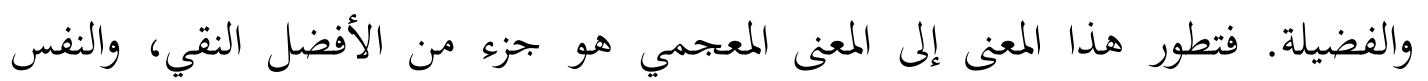

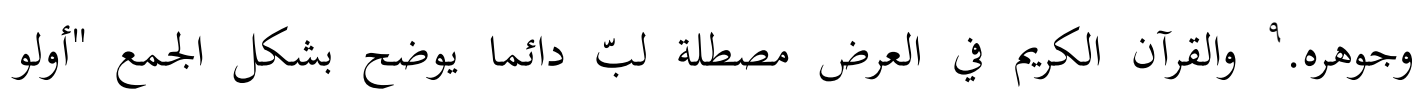

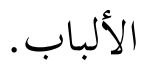

\footnotetext{
${ }^{8}$ Dawam Rahardjo, Ensiklopedi Al-Qur'an; Tafsir Sosial Berdasarkan Konsep-konsep Kunci, (Jakarta:
} Paramadina, 1996), 553

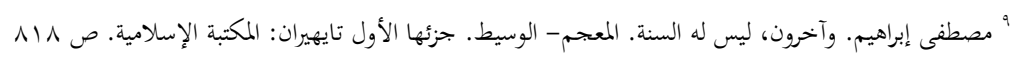


فسر علماء على وجه عموم أن تعريف كلمة أولو الألباب المتعلقة المقاطعة التي قد تم احتواء كلمة أولو الألباب، مثلا عندما فسر العلماء كلمة أولو الألباب في سورة البقرة:

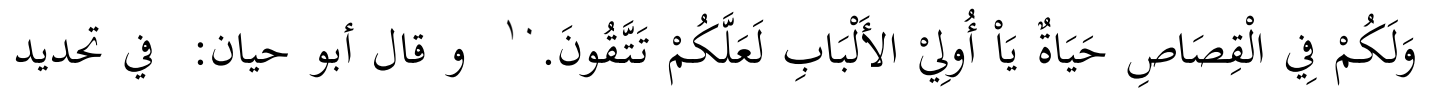

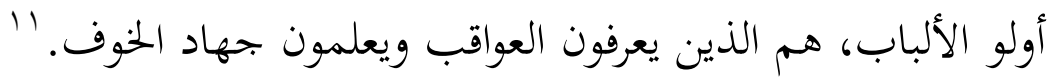
من هذه تعريفات سابقة تكون أكثر تنوعا إذا استكشاف مزيد من السادسة عشرة الآية القرآنية تتعلق بكلمة أولي الألباب عند المفسرين، سواء من المعلقين

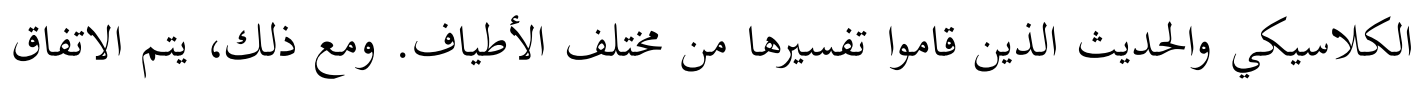
على شيء واحد عليها، وهي أن أولو الألباب هم أولئك الذين لديهم فهم عميق و سليم.

أولو الألباب هم من ينموا إيماهم أقوى من غيرهم، من حيث يفكرون ويبحثون ويفتشون دائما في القوانين بقوة، دون يأس بالخضوع والاستسلام لإرادة الله. الإيمان الذي تهري يؤسس أقوى في كل التحديق والتفسير والاستجابة للقضايا التي تنشأ في الحياة، سواء كانت تتعلق بمشاكل الفردية والجماعية، وهي مسألة العلمية والثقافية والسياسية والإنسانية و إم إلى ذلك. أولو الألباب هم أصحاب واعيون للزمان و المكان، فهذا يعني أفم قادرون على إنى

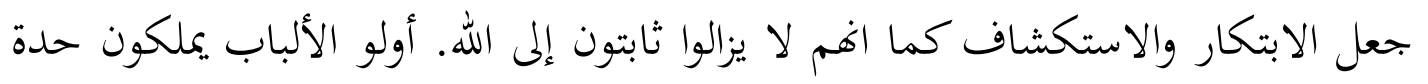
العاطفية (sharpness of intuition) والفكرية في التعامل مع بيئهم، لأن لديهم الإمكانات التي هي نادرة جدا. كلمة أولي الألباب هي التعبير في اللغات الحديثة يمكن ترجمتها بأها المثقفين الذين يؤمنون بالعقائد سليمة. كانت هذه البحموعة لديها رؤية بعيدة النظر، بالإضافة أيضا لديهم سياسة للتعامل مع المشاكل التي يواجهها المحتمع والإنسانية. تطمع ظهور هذه البمموعات من قبل جميع الأجيال في بجرى التاريخ. 


\section{- تصنيف أولي الألباب من الآيات القرآنية على أساس التحليل الدلالي}

بناء على دلالات تطبيق يظهر القرآن المكونات الدلالية أصبحت مهمة جدا لعناصر بناء القواعد في تشكيل مفردات أو كلمات القرآن. كلمة أولو الألباب لغة مأخوذة من حرف اللام "ل" و الباء "ب"، بوضع التشديد في حرف الباء. من هذه الكلمة التي تتكون من حرفين يتم تشكيل بمعنى لزوم (ضرورة، حتمية)، و ثابتية، و و

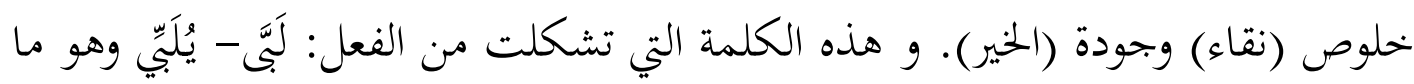
يعني أن يكسر شيئا وإزالة محتوياته، مثل الكلمة: "لببت التمر" وهي اخراج الشيء من ون داخله. ومحتويات كل شيء هي حقيقته. لذلك كلمة: "الألباب" يعني "العقل" و سبب تفضيل الإنسان على الحيوان هو عقله. المشتاق من اسم "لب" يعني الشيء الأساسي، و ولهي الجوهر، والعقل، والقلب. مثلا كلمة الرجل محبوب هو الشخص الذي لديه طبيعة

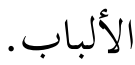
noun of ) كلمة أولي والألباب بالناحية المورفولوجية: هو اسم الجمع (collectivity "ذو". كلمة أولو هو ملحق جمع مذكر السالم (ملم) attached to the intact maskulin (plural والإعراب حسب موقعها في الجملة. من ناحية نغوية (Grammatically)، كلمة أولو الألباب في بناء جملة الآيات القرآنية مواقف متنوعة. مثلا منادى المضاف (alled

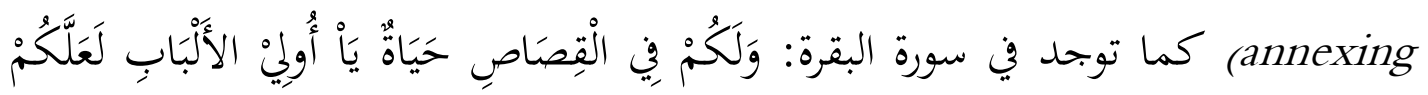

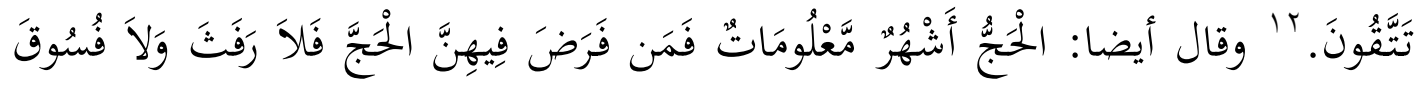

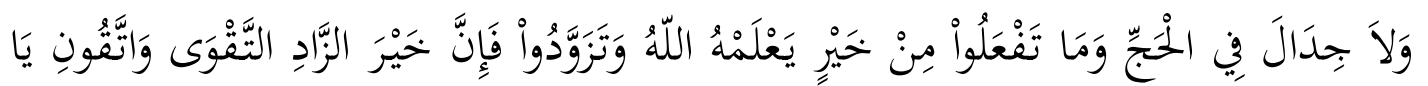

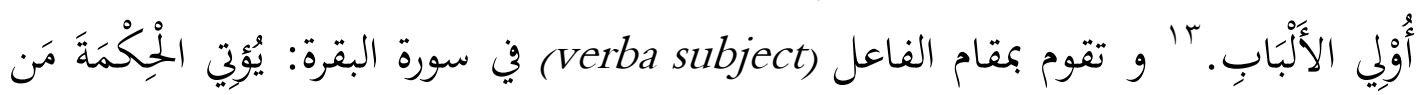

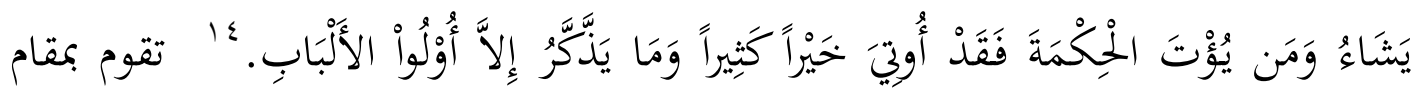


صفة الموصوف، في سورة آل عمران: إِنَّ فِي خَلْقِّ السَّمَاوَاتِ وَالأَرْضِ وَاخْتِلاَفِ اللَّبَّلِ

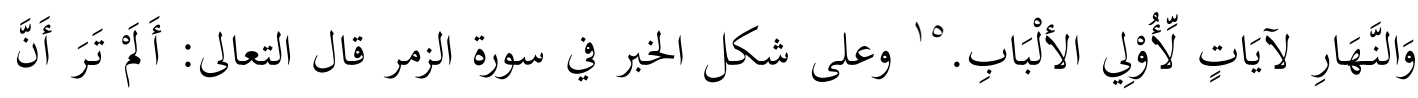

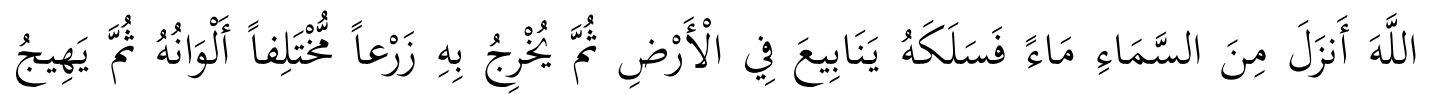

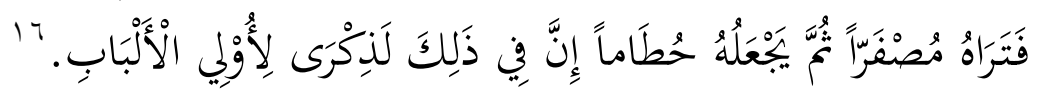

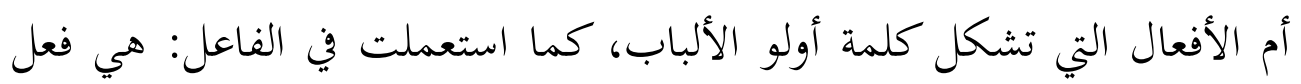

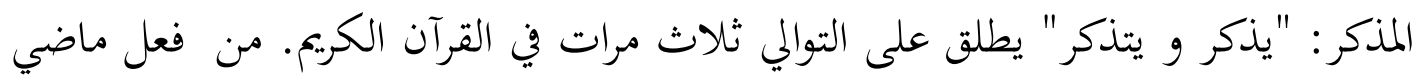

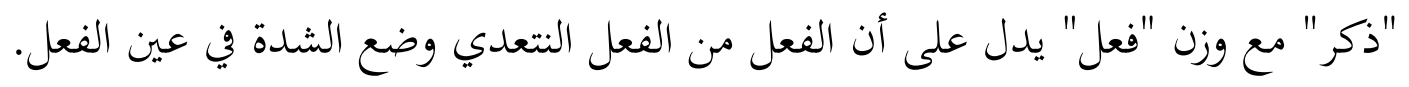
من وجهة النظر النحوي (Grammatically Perspective) العلاقة بين أولو الو

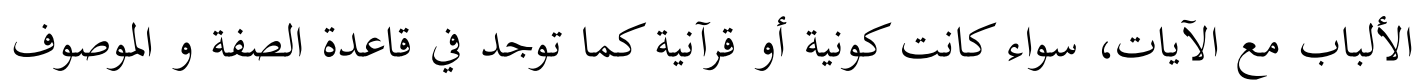

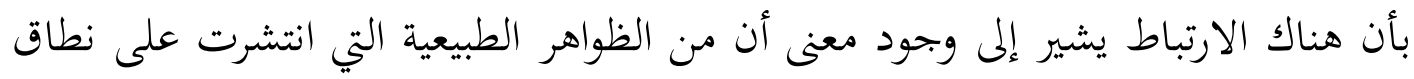

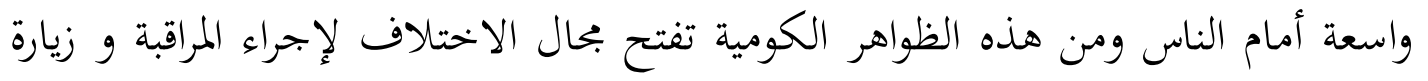

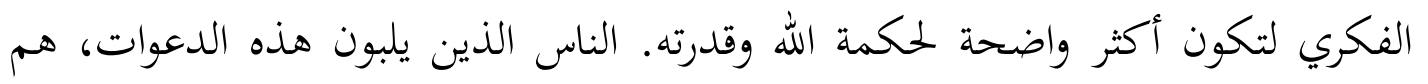
أولو الألباب كما واضح الله التعالى في سورة آل عمران السابقة.

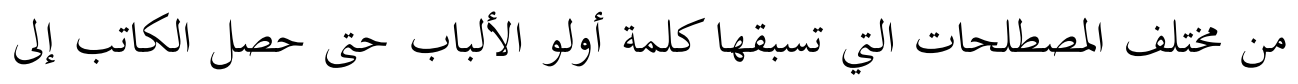

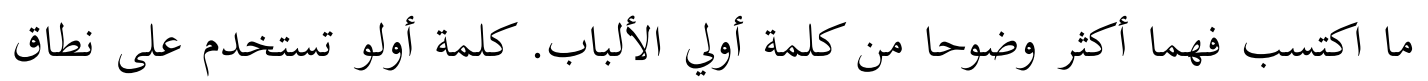

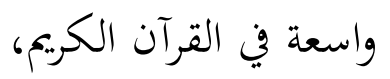

\section{- -}

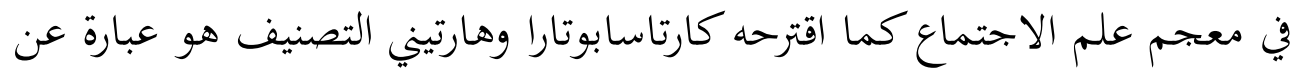

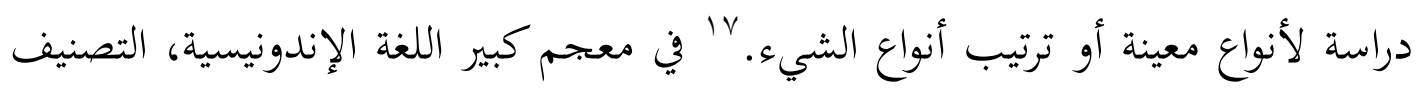

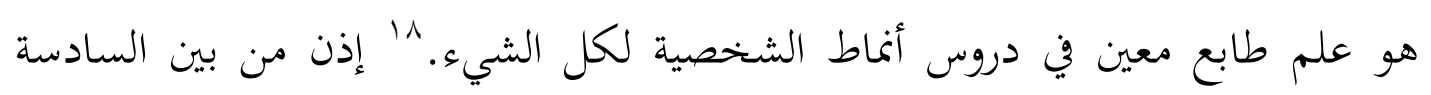

$$
\begin{aligned}
& \text { 10 القرآن الكريم في سورة آل عمران: . } 19
\end{aligned}
$$

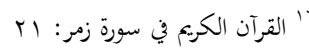

${ }^{17}$ G. Kartasapoetra, Hartini, Kamus Sosiologi dan Kependudukan, Jakarta : Bumi Aksara, 1992) 92

${ }^{18}$ Kementerian Pendidikan dan Kebudayaan R.I Jakarta, 1995) 102 
عشرة الآية القرآنية عن أولي الألباب تحليلها على أساس التحليل الدلالي، لتصنيف أولو

$$
\text { 1. الألباب ويككن تقسيمها فيما تالي: }
$$

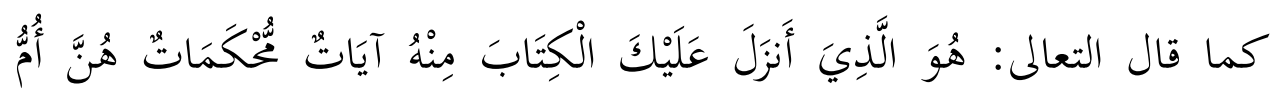

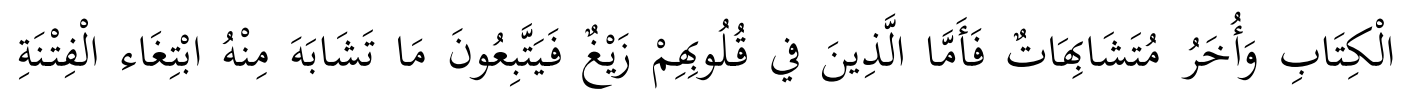

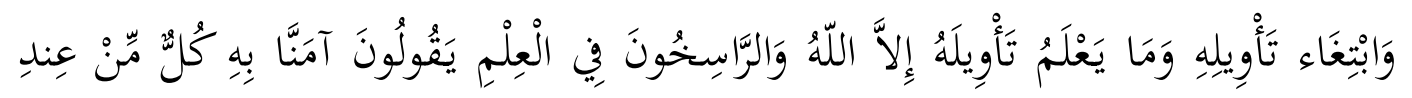

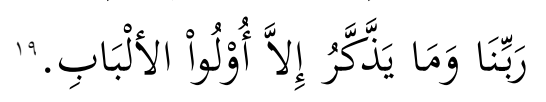

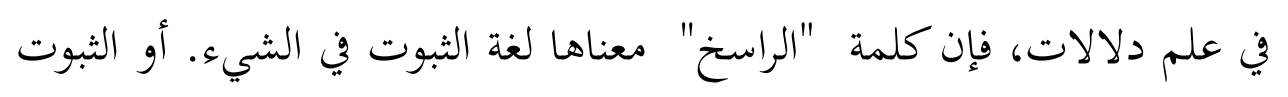

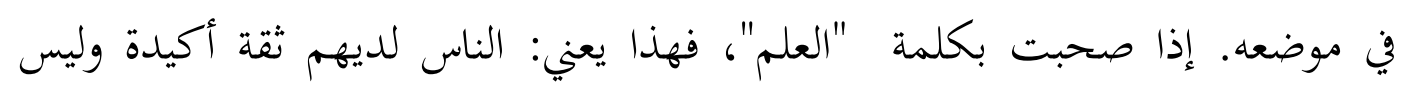

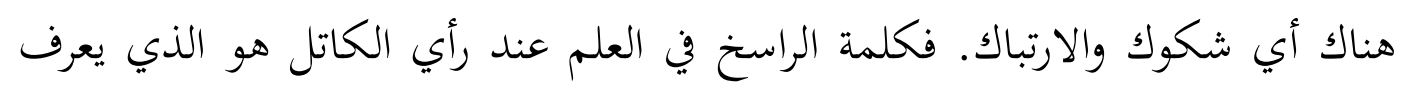
الله مع صفاته وبالحجية قطعية يقينية.

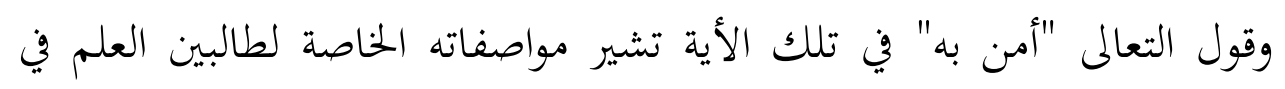

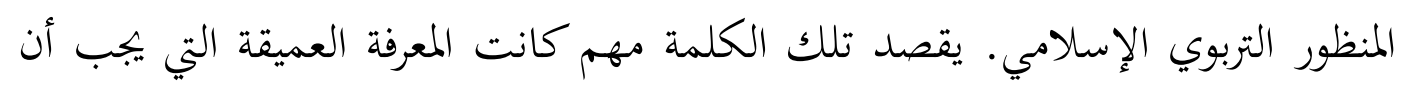

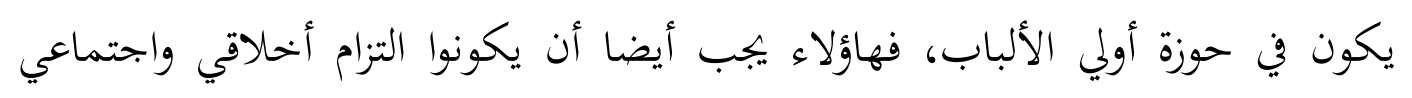
جيدا.

لتحقيق مستوى من الراسخون في العلم، لا يمكن بحاهلها الحواس البشرية

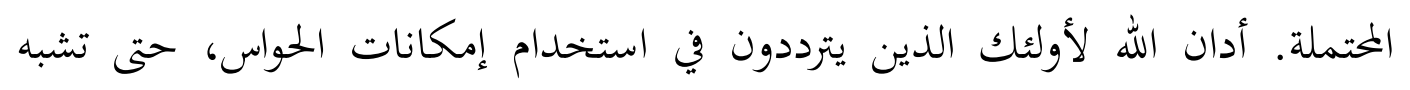

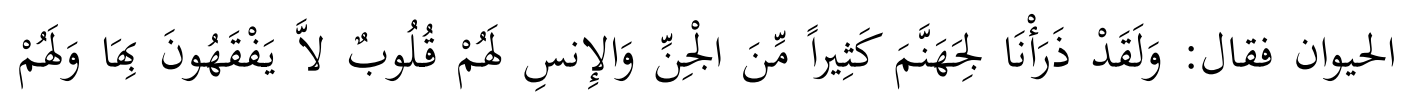

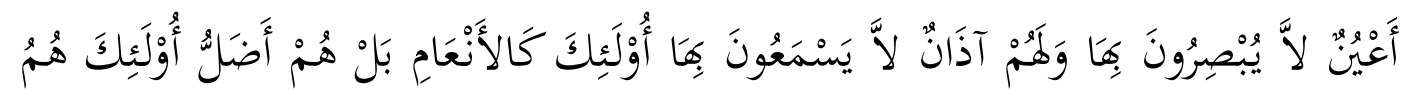

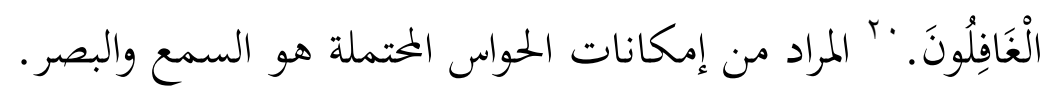




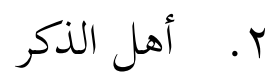

التذكر هو وظيفة العقل أعلى المنزلة والذاكرة مكان لتخزين المعرفة والمعلومات التي تم الحصول عليها البشر لاستخدامها عند الحاجة. لا يستطيع الإنسان أن يعيش تماما دون الذاكرة والتذكر. ثم الشخص الذي يفقد ذاكرته فقد فقد عليه نفسه، لأنه ليس لديه ذاكرة، ووليس له تاريخ الخاص.

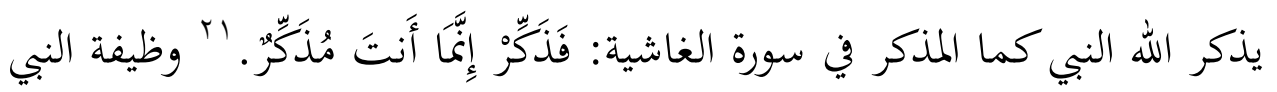
كالمذكر مرتبطة بنشاط علمي أولي الألباب مع موقف حرج بناءة. ويبدو موقف حرج إذا واجهت طابع ذكرى مع واقع المشاكل الملموسة. يعطى تلاوة أو تلقى تحذيرات. الإجراءات التذكير بأن تنشأ عندما يكون الشخص ليكون حاسما. لذلك، أولو الألباب في حد ذاته يوفر موقف حرج أو قلق التنبيهات.

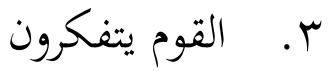

المعنى المعجمي، من كلمة "فكر -يفكر" هي التعامل والتحليل. ومن أصيل هذه الكلمة شكلت كلمة تفكر بإضافة التاء "ت". في كتاب مفرادات ألفاظ القرآن، قال الأصفحاني: الجوال لتلك القوة بحسب نظر العقل بَ، أي ممارسة المعرفة بقوة الاستطلاعية واستخدام الذكاء، أو العمل العقلي في مشكلة لتحصيل حلها بالعبارة الأخرى، الأنشطة العقلية للإفصاح أو حل المشاكل. مثال واحد من مشاركة أولي الألباب في نشاط التفكير في القرآن الكريم قول التعالى: إِنَّ فِي خَلْقِ السَّمَاوَاتِ وَالأَْْضِِ

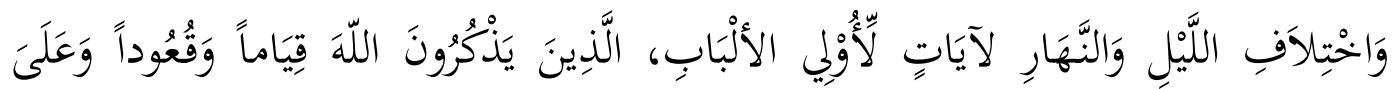

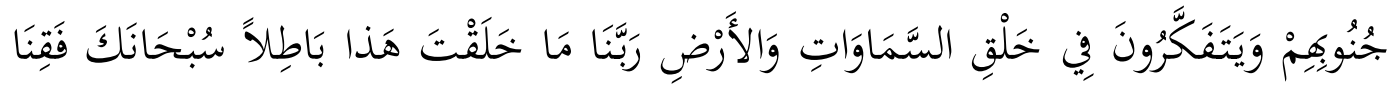

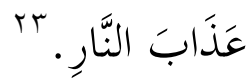


ذكر التفكر هو التفكير التحليلي لأن لديه حس الإبداع، والتفكير في الدراسة

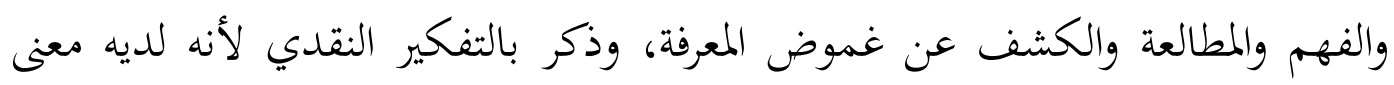

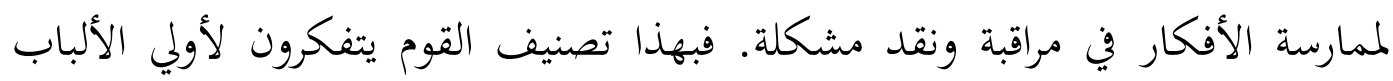

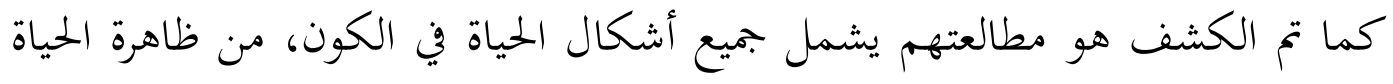
الاجتماعية، والحياة الطبيعية على وجه الخصوص، وكذلك الظواهر الطبيعية العظيمة.

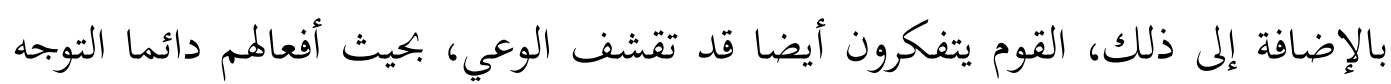

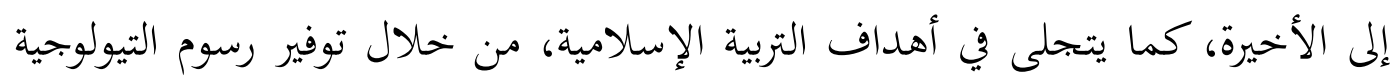
لكل خطوة وتوجيه عملها.

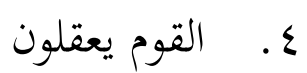

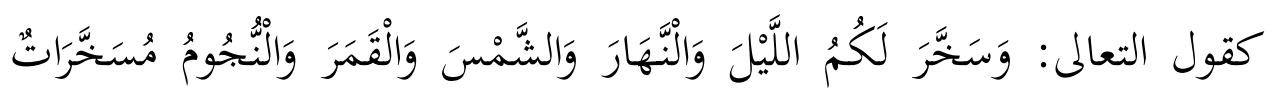

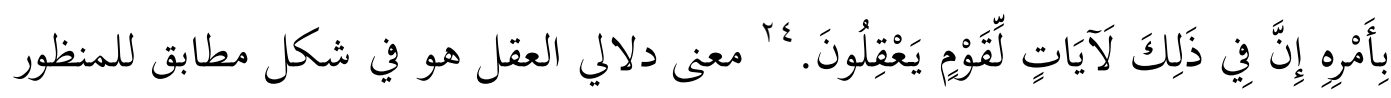

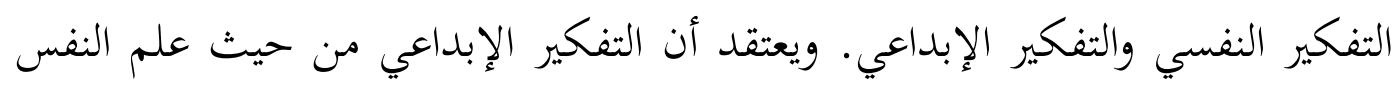
أن استخدام طريقة جديدة منتجة. بعض صيغ التفكير بتميعها في التفكير الإبداعي في علم النفس هو استنتاجي

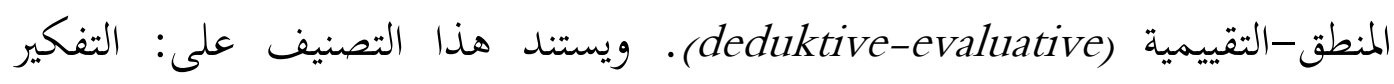
الاستنباطي أكثر قياسي، منتجة وخلاقة، ومبتكرة، في حين أن التفكير التقييمي يساعد التصني

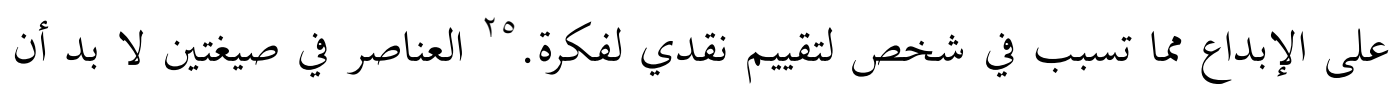

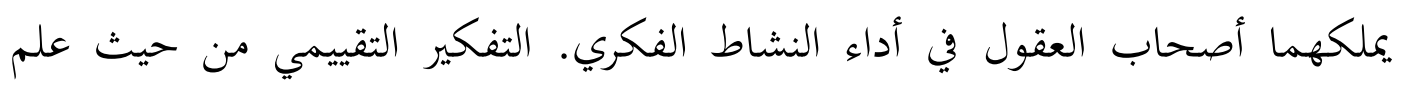

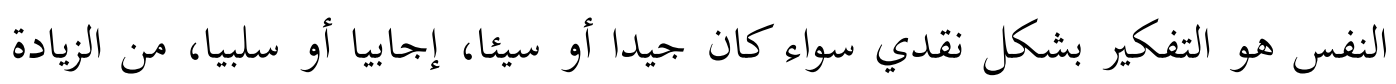
أو النقص وما إلى ذلك،

${ }^{25}$ Morton Hunt, The Universe Within: A New Science Explores the Human Mind, (New York: Simon and Schuster, Paperback - June 1, 1983). 284 


\section{- تفريق أولي الألباب والعالم والفلسوف}

وفقال جلال الدين رحمات: أن كلمة أولي الألباب يمكن وصفها من قبل الآيات

القرآنية سمي ب"روسيان الفكر"rrangan fikr) وقد أسس مصطلح روسيان الفكر لأول

مرة في منتصف القرن 9 ا من قبل زعماء إيران العلمانية التي تتبع وتعجب وتتأثر أفكار فلاسفة أوروبا في القرن م | في فترة التنوير. "روسيان الفكر" مشتقة من الكلمة الفارسية التي تعني "المفكر المستنير". وفسر جلال الدين رحمات "روسيان الفكر" إلى الإبحليزية "الفكري/ المثقف" أو "المفكرين الأحرار" (free thinkers) .

عموما من بين هاؤلاء الثلاثة ، أولو الألباب والعلماء المختصون والفلاسفة يخضعون ويركزون عملية التفكير ويبدلون جهودهم في إخراج ما فيها من الأدهان والفؤاد. و في هاية أولو الألباب لديها مزايا أكثر من كليهما. وأخيرا يبدو أن أولي الألباب هو شخصية المفكري والمثقف الحقيقي. أولو الألباب لا بد أن يأتي من المتعلمين أو العلماء

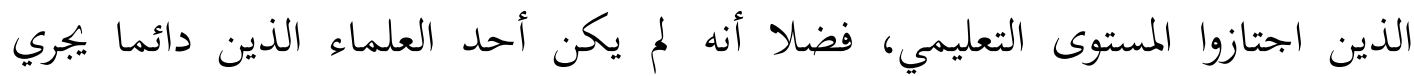
تحقيقات مشغولية في مختلف المختبرات، ولكن أولي الألباب هي بحموعة من الناس دون

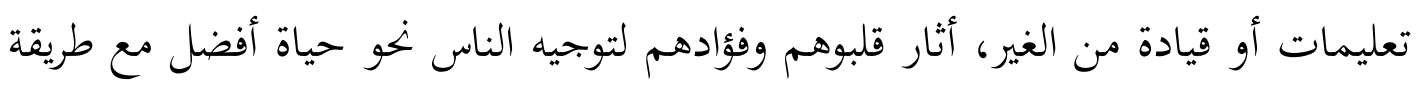
لاستيعاب كل تطلعات أولئك الذين وضعت في وعاء الأمل الأعلى (lofty ideals). أولو الألباب موجهة للجماهير أو الأمة. وقيل أهم يحاولون دائما لتشكيل والتأثير وبناء بيئة مع بحموعة متنوعة من الأفكار التحليلية والمعيارية. كان ينظرون إليهم باعتبار حرجة وحساسة لقيمة النظام، وشرح الأهداف والأمل الأعلى التي هي بمثابة الروح التي تقود إلى التقدم. وفقال شريعتي: عالم - مع مظهر مميز -، وذلك لتمييز نفسه مع أولي الألباب. والعلماء المختصون (scientists) يشغلون أنفسهم مع الأشياء المادية (physical) وعشاعاتما. العلم هو الصورة الذهنية للإنسان مع أشياء ملموسة ونتائج الروابط المختلفة حيث المبدأ والجودة وخصائص البشرية والطبيعية والمكونات الأخرى. العلماء يحاولون ربط

\footnotetext{
${ }^{26}$ Ali Syari'ati, Membangun Masa Depan Islam, (Bandung: Mizan, 1993) 16
} 
أنفسهم مع الكائنات البحثية. على سبيل مثال تفتيش الكائنات الحياة مما أدى إلى علم النفس والملاحظات في النباتات حتى تحصل النتائج في علم النبات (botany). أما فلسوف مثل آريسطوتيلس كما نقله شريعتي كان يميل إلى التأمل والمفاهيم.

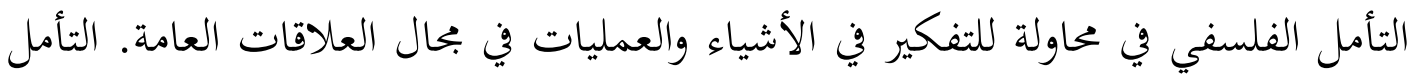

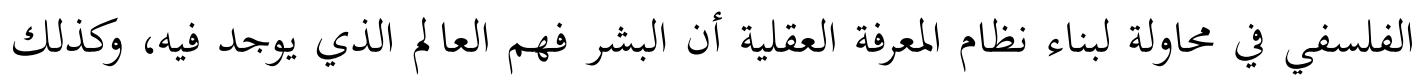

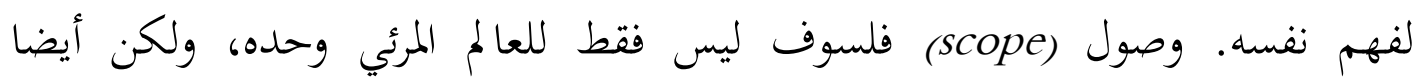

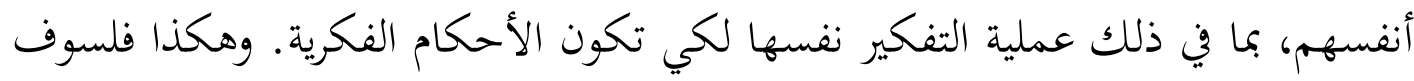

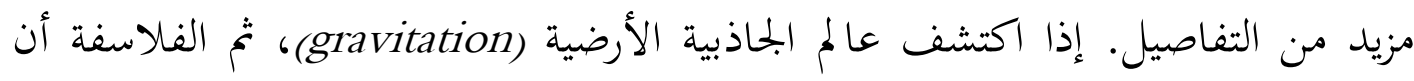

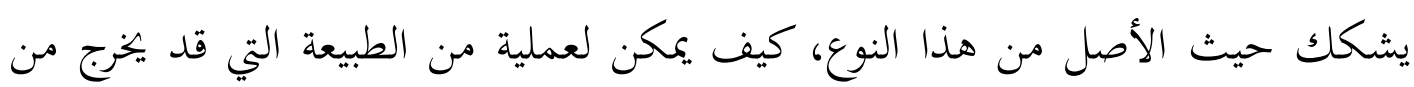
الإطلق.

وجه الإفتراق بين العلماء والفلسوف هو أن هما لا يشركا مشاكل الجختمع، مثل

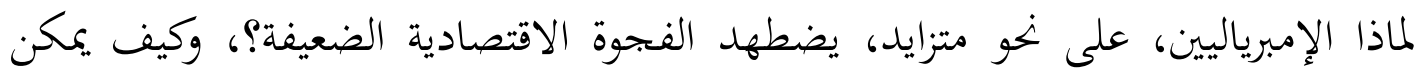

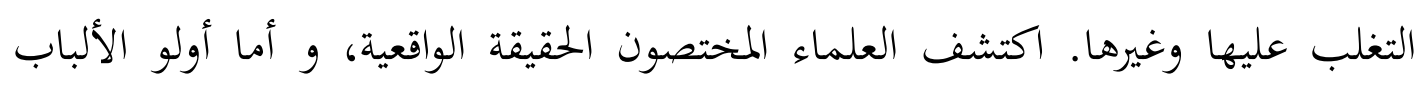

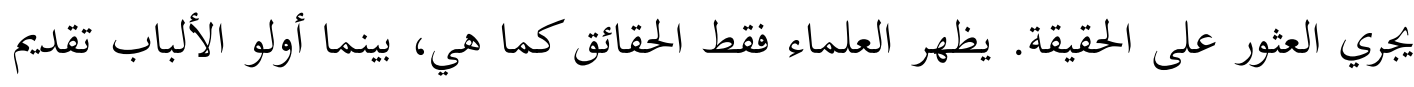

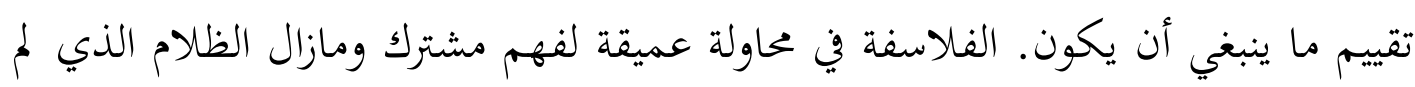

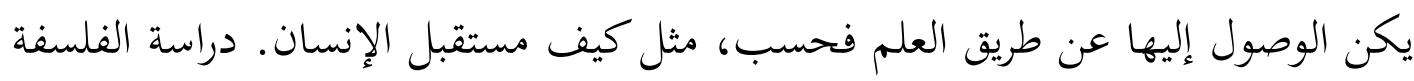
في حالة تشكك إمكانية مثالية (The ideal possibilities)، الإنقضاض فئن في الإنسان. دراسة الحقيقة

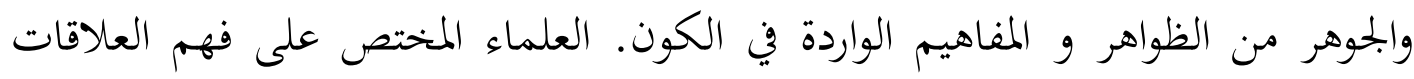

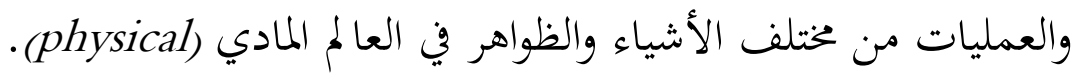

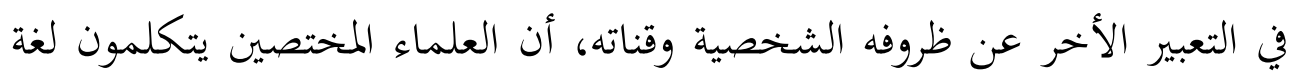

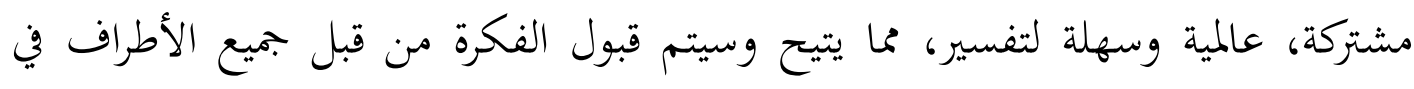

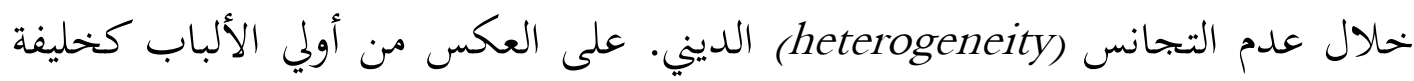

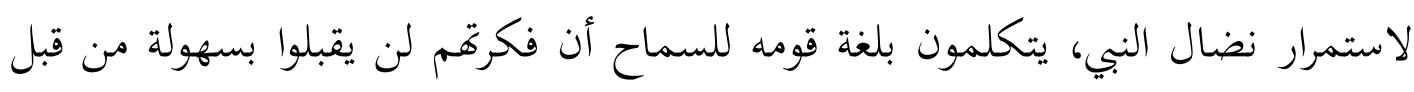

${ }^{27}$ Ali Syari'ati, Membangun Masa.... 116 
الجماهير مع منطقة معينة. أولو الألباب تتسرب في وسطهم، ويقوم بتلويح راية كوسيلة لبدء مهمتهم.

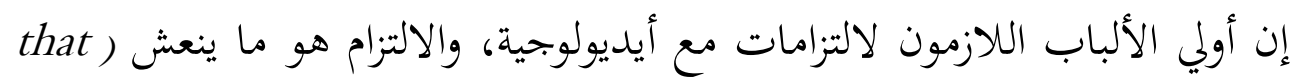

(animates

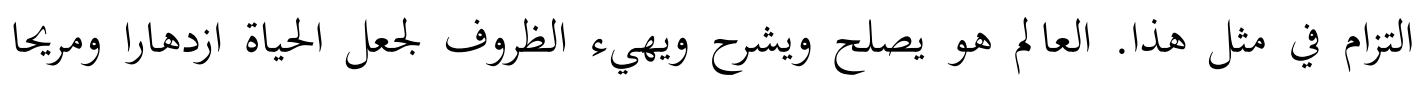

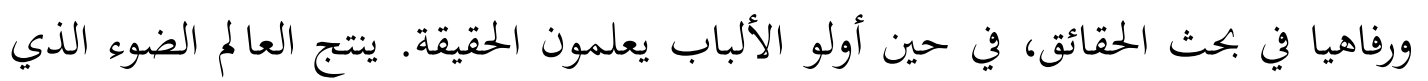

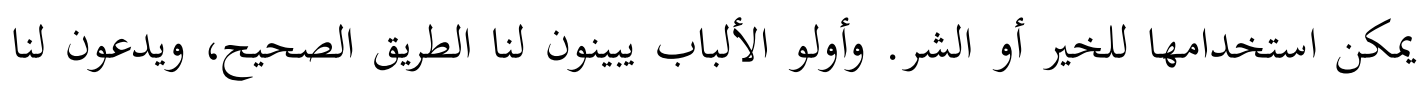

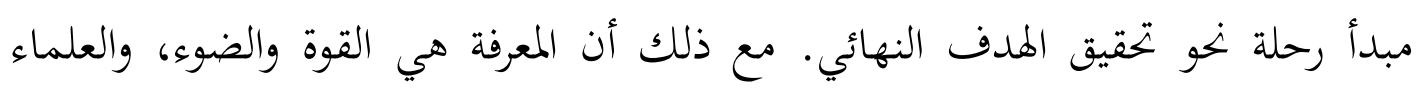

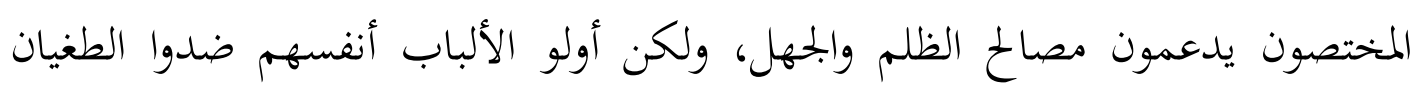

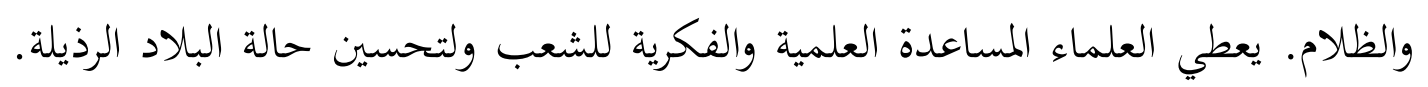

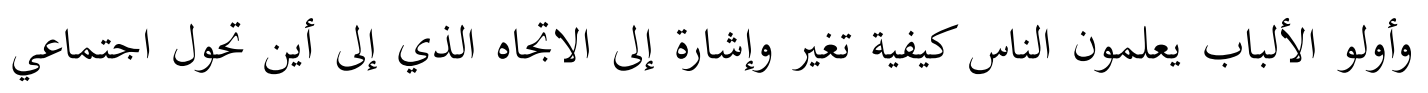

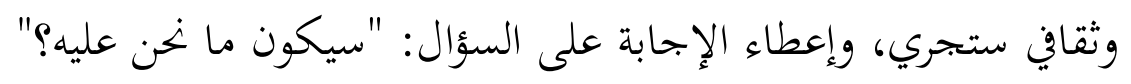
- المثقف المسلمي وخصائصه

قال زين الدين سردار، المثقف المسلمي هو بحموعة متعلمة إسلامية أن له مزايا

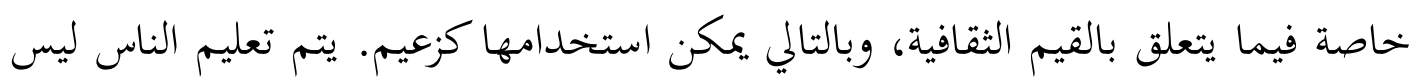

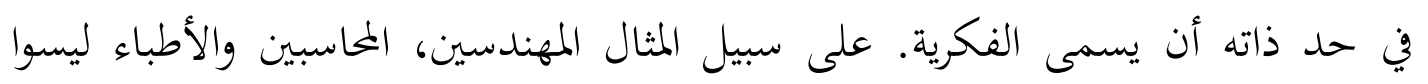

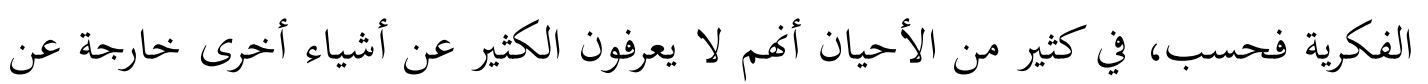

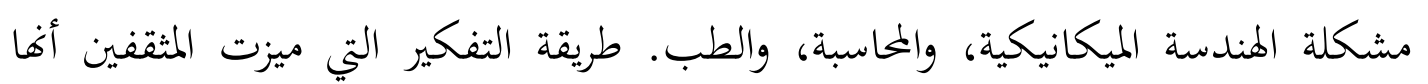

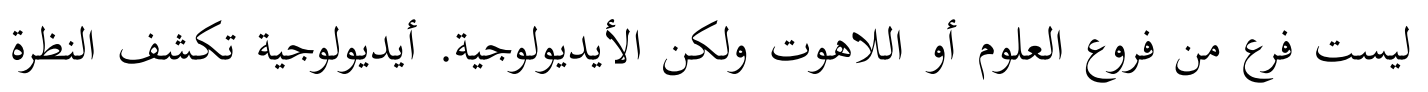

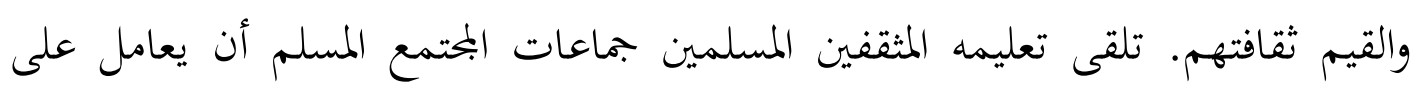

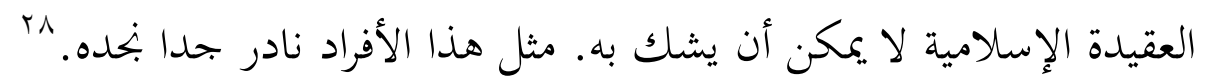

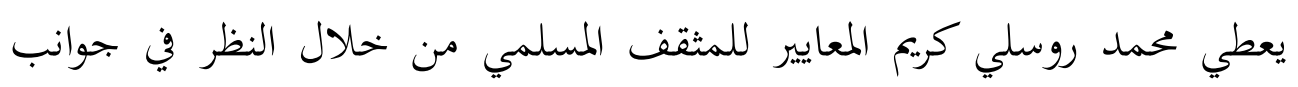

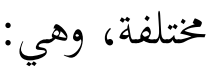

\footnotetext{
${ }^{28}$ Zainuddin Sardar, Rekayasa Masa Depan Peradapan Muslim, (Bandung: Mizan, 1993) 88
} 
ا ـ إذا نظرنا إلي المثقف المسلمي من ناحية الخلفية التعليمية، على الأدنى من الكلية التي قد مرت به في وقت ماض، درجة الدكتوراه.

ץ. المسافة بينه وأمة المسلمين. بسبب النزاهة (integrity) التي تعكس قيم وتعاليم الإسلام،

$$
\text { وكذلك في صالح الإسلام. }
$$

$$
\text { r. له ميول من حيث الأنشطة التي تعكس مصالح المسلمين: }
$$

أ. غالبا ما يدعى لإلقاء محاضرة/ خطبة من المستوى المحلي إلى المستوى الوطني. ب. وفي الغالب أيضا ما يشارك / يضمنه في المناقشات وورش أو حلقات العمل

$$
\text { والندوات حول الإسلام. (Workshop) }
$$

ج. يركز نفسه في اهتمام كبير لتنمية الفكر الإسلامي. د. و ييكتب مقالات علمية عن مزية الإسلام دفاعة عنه.

ع. أن يكون نموذجا ومرجعا يحتذى به في البيئة الإسلامية. (Resources Person) ه. غالبا ما يشارك في المؤسسة سواء كانت الحكومية أو الأهلية أو في بحتمع معين. ج. لـديه قلق أكاديميكي والتزام القوي لقيم وتعاليم الإسلام الذي يضيء في الفكر والمواقف

$$
\text { وسلوك كل يوم باستمرار. }
$$

من وضع روسلي كريم المعايير السابقة التي تنص على أن "ما لا يقل عن حضور أي وقت مضى في إحدى الجحامعات" حتى يعطي الشعور والتصور بأن المسلمين المتعلمين

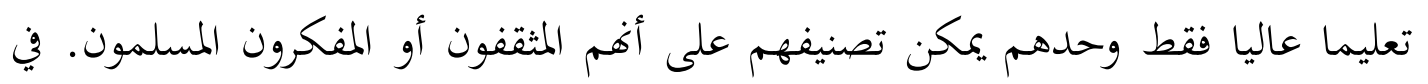
حين هم الذين لمج يتموا تعليمهم في الجامعات لا يمكن تصنيفهم على أفم المفكرين المسلمين. ثم يعطي محمد روسلي كريم المعايير التي يجب أن تكون مملوكة من قبل المفكرين المسلمين المرتبطة بالأنشطة المهمة التي سيفعلوها، وهي: ا. في منهج تفكيره. يمكننا أن نرى في عملياته من أن يكون بالتصور الإسلامي، ثم يقوم بمحاولة لمعرفة مختلف المشاكل والإسلامية، ويكتبها يناقشها ويدرسها للأمة.

${ }^{29}$ Muhammad Rusli Karim, Dinamika Islam di Indonesia: Perspektif Sosiologi, (Yogyakarta: PT Hanindita, 1995) 112 
r. التحريك أو التئر في فهم حقيقة الإسلام والمختمعات الإسلامية. وهذا مككن لأفها قادرة

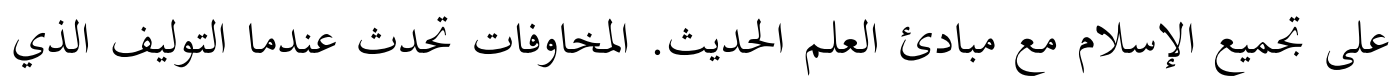

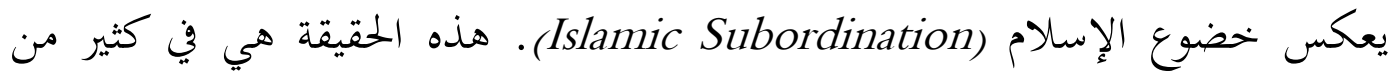
الأحيان مصدرا للصراع في الفكر الإسلامي المعاصر.

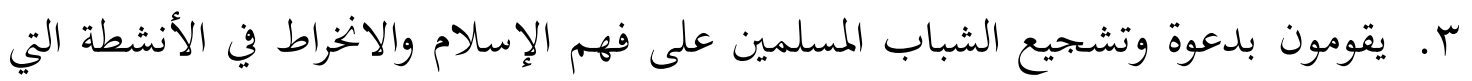

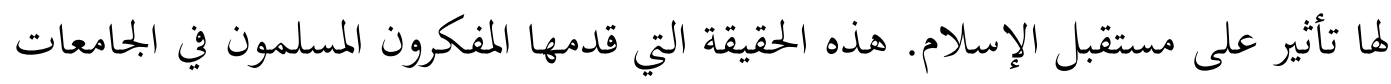

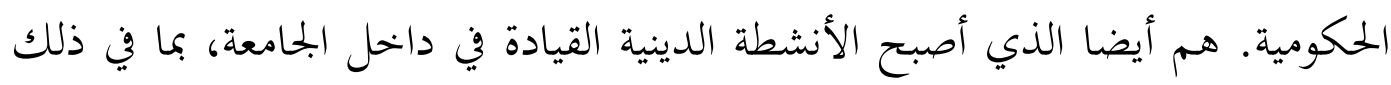

$$
\text { أنشطة لتشجيع منظمات الطلاب وشباب الإسلام. }
$$

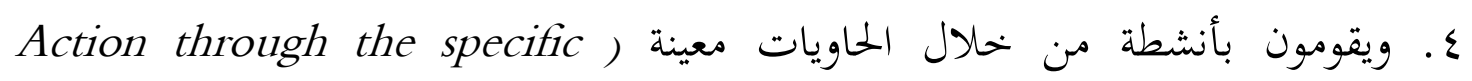
container

$$
\text { والعمل في بحتمع معين وهو الدافع الإسلام، إما سرا أو علنيا. }
$$

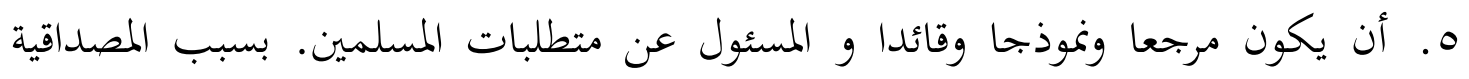

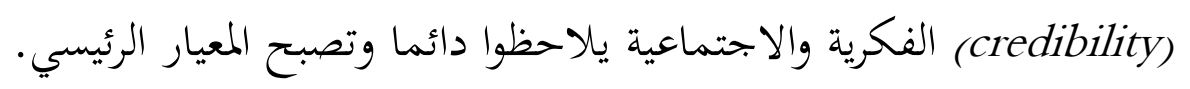

7. مواجهة تيارات خختلفة (Counter the various currents) من الفكر الذي مضللة ينظر إليها من وجهة نظر الإسلام. وغالبا ما يطلب آرائهم ويعرض وسائل الإعلام المختلفة بشأن بحموعة متنوعة من القضايا المتعلقة بالإسلام والبحتمعات الإسلامية. V. المشاركة بنشاط في غختلف اللقاءات العلمية والإسلامية. يصبحون وفدا إسلاما للأنشطة

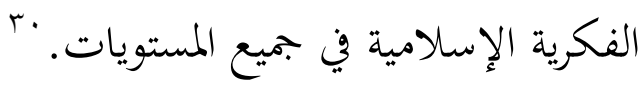

$$
\begin{aligned}
& \text { - حقيقة مفهوم أولي الألباب }
\end{aligned}
$$

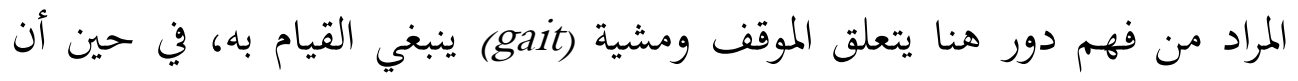

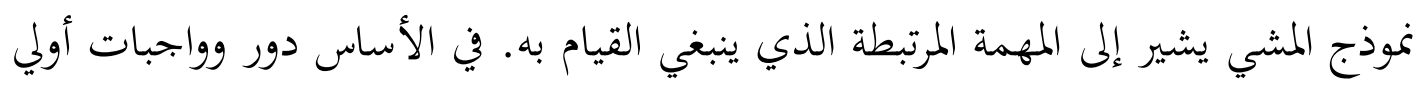

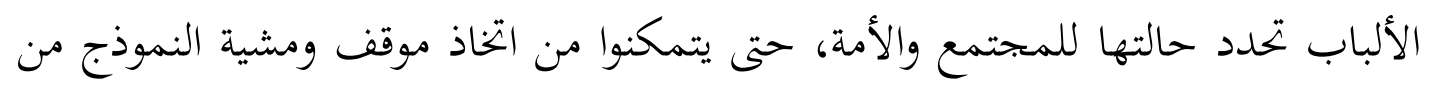
وجود سلطة تقديرية في خضم بحتمع أمر مهم جدا لتقدم الحضارة الإنسانية.

\footnotetext{
${ }^{30}$ Muhammad Rusli Karim, Dinamika Islam...,
} 
لمعرفة وظيفة أولي الألباب، كيف الأخلاق و أداء واجباتم والأساليب المناسبة

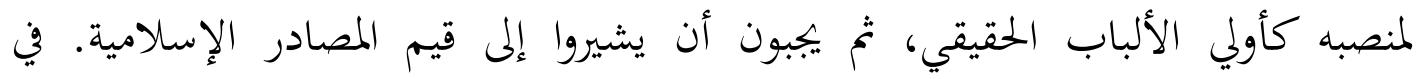

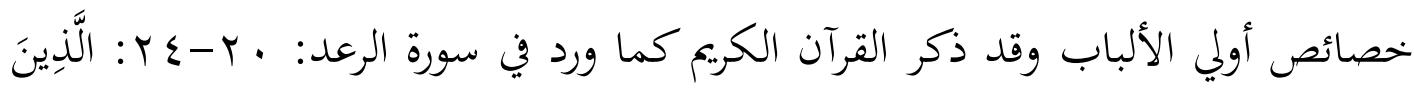

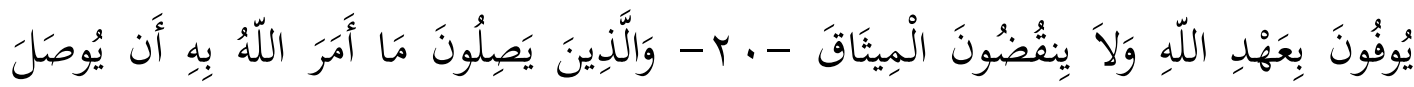

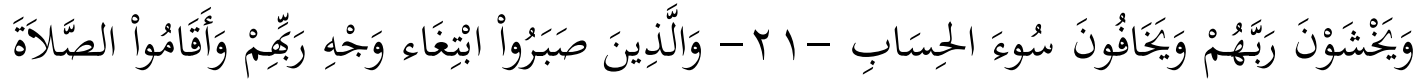

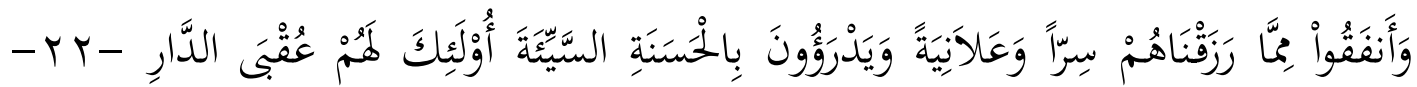

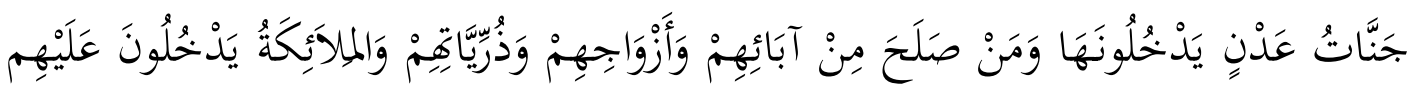

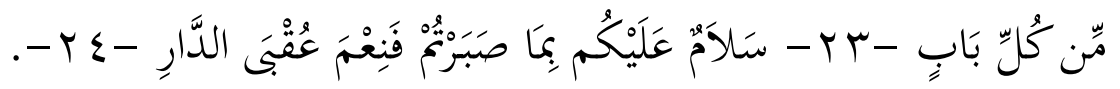

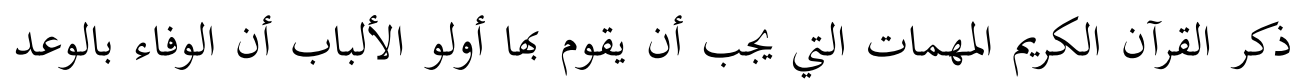

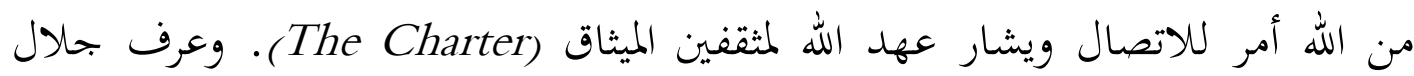

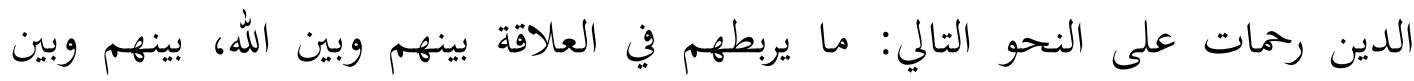

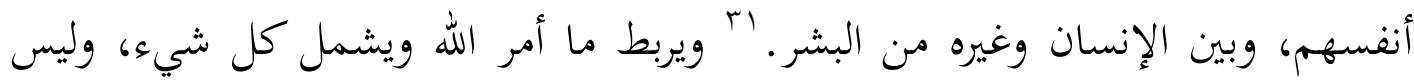

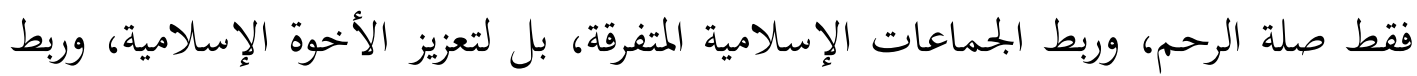

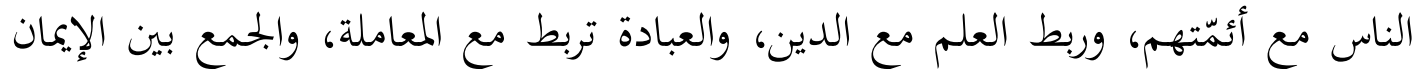

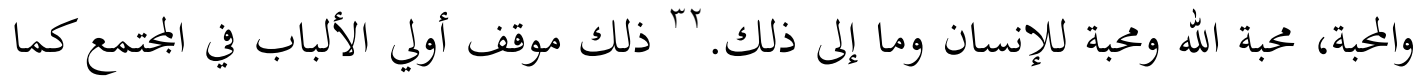
هو توحيد منقسم بين الناس، ويشثون نقطة الإلتقاء لتدفق الفكر ويربط كل الاختلافات.

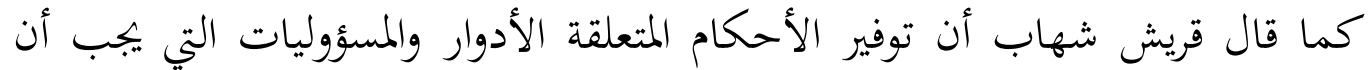

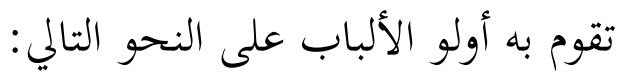
ا. إن أولي الألباب مطلوب للدراسة بشكل مستمر، ويدرسون الكتب المقدسة من أجل المابل ممارسة ويصفون القيم ذات طبيعة عامة التي يمكن استخلاصها منها القرائن التي يمكن

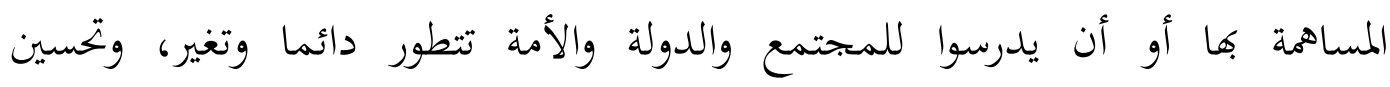
احتياجاتم. أو بعبارة أخرى؛ يجبون أن يكونوا قادين على ترجمة هذه القيم ليتم تطبيقها

${ }^{31}$ Jalaludin Rahmat, Islam Alternatif. (Bandung: Mizan, 1999). 224 
في بناء هذا العالم. لأن هذا هو الهدف القرآن الكريم في سورة البقرة: بآب، وأنه أيضا يهدف لهم الأوامر في تعلم وتعليم دائما. r. كانت مطلوبة أيضا لمواصلة الاكتشافات آيات الله في الكون، سواء في البشر فرادى أو في بحموعات، وكذلك يراقبون هذه الظواهر الطبيعية. هذا يتطلب منها أن تكونون

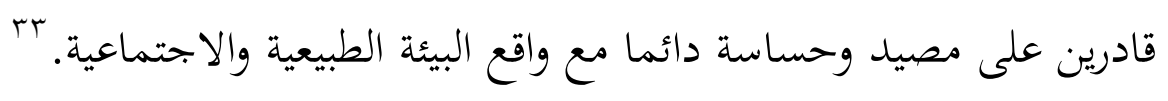

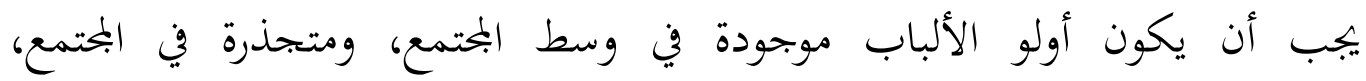

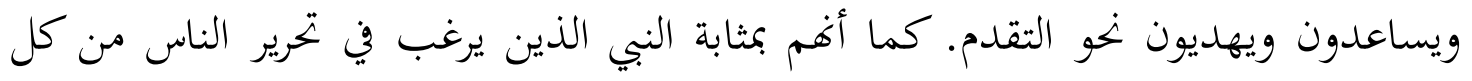

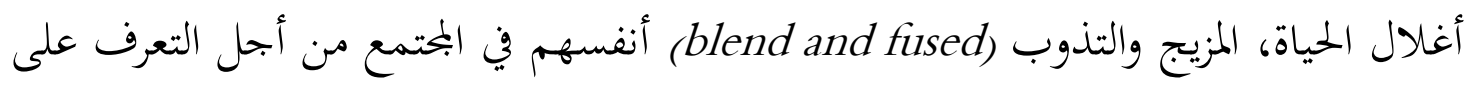

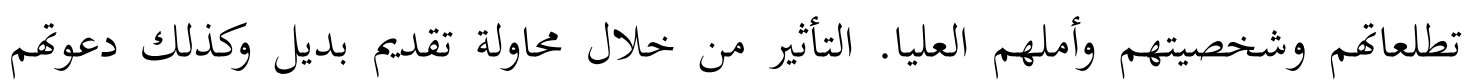

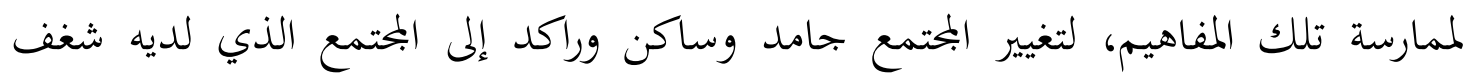

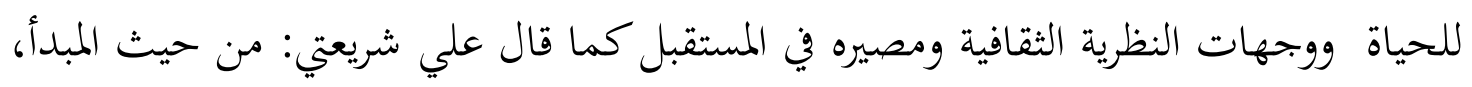

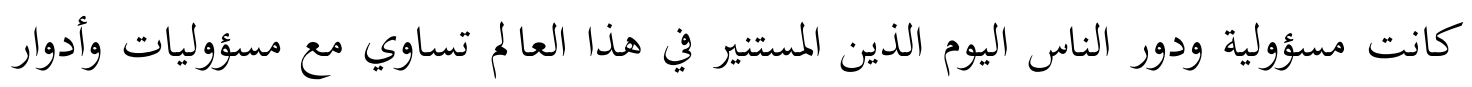
الأنبياء ومؤسسي الديانات الكبرى، وهم القائدون الذين يشجعون لإنشاء التهاء التغييرات الهيكلية

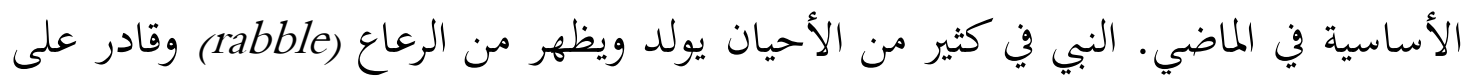

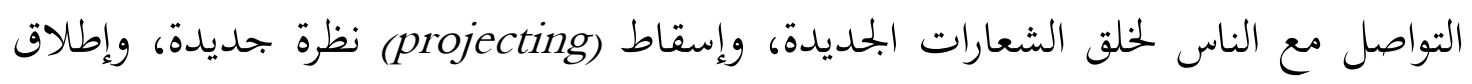
حركات جديدة، وتلد طاقات جديدة في قلب الوعي بحتمعهم. وكانت الحركات الثورية

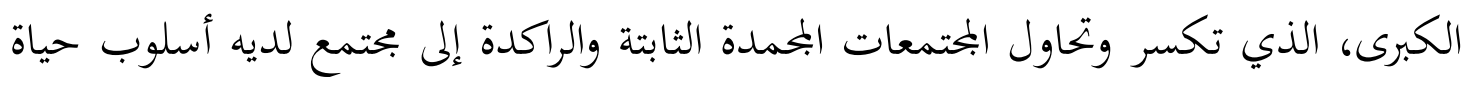

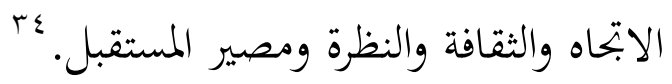

\footnotetext{
${ }^{33}$ M. Qurai Syihab, Membumikan Al-Qur'an, (Bandung: Mizan, 1999), 390.
}

${ }^{34}$ Ali Syari'ati, Membangun Masa Depan Islam.... 68 


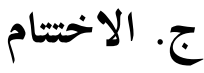

ويستند تصنيف أولو الألباب على تحليل آيات القرآن هو الراسخون في العلم،

والقوم يتفكرون، أهل الذكر، وأصحاب العقول. ويمثل هذا النموذج عن طريق القرآن

الكريم لوصف شخص لديه التزام لاهوتية أو تيولوجية (teologis) في كل المواقف

والسلوك، بالإضافة إلى ذلك، القوم يتفكرون أيضا قد تقشف الوعي، بحيث أفعالهم دائما

التوجه إلى الأخيرة ، من خلال توفير رسوم اللاهوتية لكل خطوة وتوجيه عملها.

ظاهرة أولي الألباب هي ظاهرة التربية الإسلامية. في هذه الشهادة يتم عثور

النشاط نخو التعليم، والمبادئ السليمة والكريمة وخصائصها والأهداف التعليمية للإسلام.

وعلاوة على ذلك، والآثار المترتبة على التربية الإسلامية هي تعليم الرجل كله ينعكس في ولئ

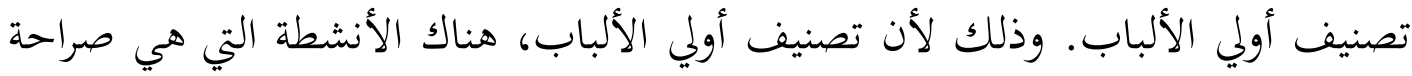

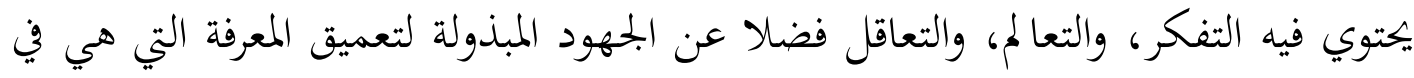

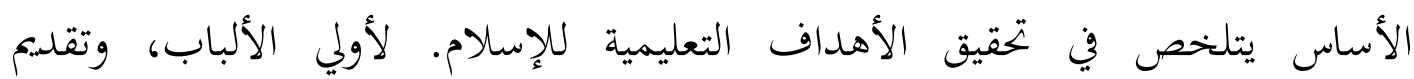

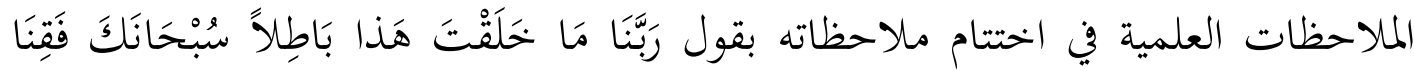

عَذَابَ النَّارِ، هذا هو الاعتراف صادق بعد استكشاف عميقة على الظواهر الطبيعية،

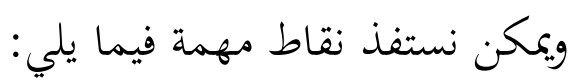

1. إن أولي الألباب جمع دائما الإيمان والعلم والأعمال الخيرية. يجلب مبلم معا أيضا

جوانب الشريعة الإسلامية، والإيمان والأخلاق والعبادة. وتعقد بثابت هذه المبادئ

وتطبيقها في وسط البحتمع.

r. إن أولي الألباب بالإضافة إلى تقديم المساعدة إلى البحتمع العلمي، كذلك يشير إلى

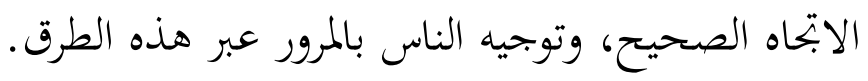

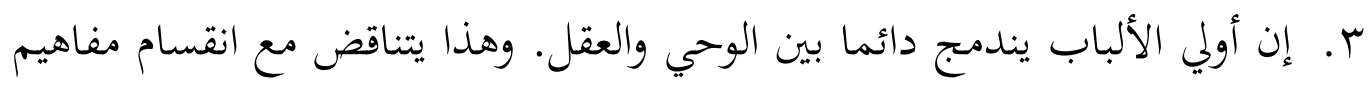

علم العلماء غير المسلمين الذين يفرقون و يقومون بفصل بينهما حتى في فاية

المطاف يولد ما سميت بالعلمانية. 


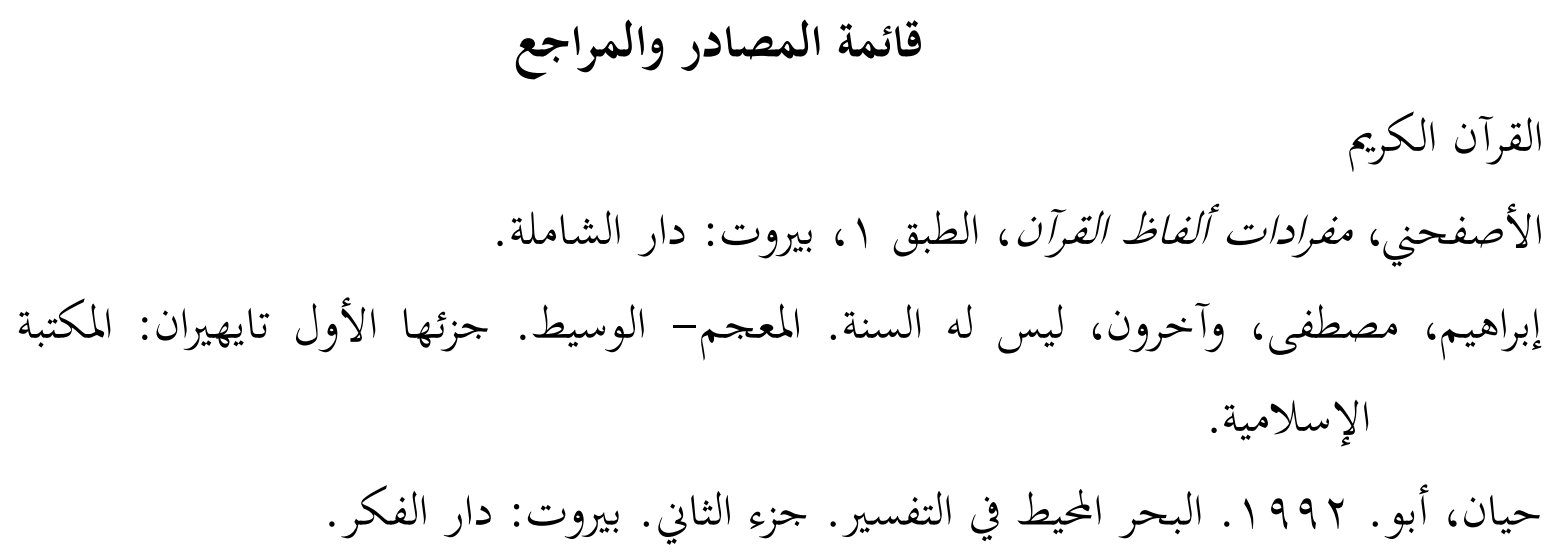

Hunt, Morton 1983, The Universe Within: A New Science Explores the Human Mind, (New York: Simon and Schuster, Paperback.

Izutsu, Toshihiko. 2003, Relasi Tuhan dan Manusia: Pendekatan Semantik terhadap AlQur'an, Penerj. Agus Fahri Husein, dkk. Yogyakarta: Tiara Wacana.

Kartasapoetra, G. dan Hartini. 1992, Kamus Sosiologi dan Kependudukan, Jakarta: Bumi Aksara.

Hidayat, Komaruddin. 1996, Memahami Bahasa Agama sebuah kajian Hermeneutik, Jakarta: Paramadina.

Masthuhu, 1994, Dinamika Sistem Pendidikan Pesantren. Jakarta: INIS.

Munir, Abdul Mulkan. 1994, Paradigma Intelektual Muslim; Pengantar Filsafat Pendidikan Islam dan Dakwah, Yogyakarta: Sipres.

Nasution, Harun. 1997, Akal dan wahyu dalam Islam, Yogyakarta: UII Press.

Rahardjo, Dawam. 1996, Ensiklopedi Al-Qur'an; Tafsir Sosial Berdasarkan Konsepkonsep Kunci, Jakarta: Paramadina, 1996.

Syari'ati, Ali. 1993, Membangun Masa Depan Islam, Bandung: Mizan.

Rahmat, Jalaludin. 1999, Islam Alternatif. Bandung: Mizan.

Rusli, Muhammad Karim. 1995. Dinamika Islam di Indonesia: Perspektif Sosiologi, Yogyakarta: PT Hanindita.

Syihab, M. Qurais. 1999. Membumikan Al-Qur'an, Bandung: Mizan.

Sardar, Zainuddin. 1993, Rekayasa Masa Depan Peradapan Muslim, Bandung: Mizan.

Usa, Muslih \& Aden Wijdan SZ, 1997, Pendidikan Islam Dalam Peradaba Industrial, Yogyakarta, Aditya Media. 